\title{
Researching game-based learning practices in Aotearoa New Zealand
}

\author{
RACHEL BOLSTAD
}

\section{KEY POINTS}

- Game-based learning (GBL) encompasses all sorts of learning that involves games, including gameplay, game design, and gamification.

- There is a mixture of curiosity, enthusiasm, and uncertainty in the education sector about where games "fit" into learning.

- Traditionally, games were part of the "cultural commons" of all communities. In the last century, games and game design became hot commodities, and understanding their role and contribution to learning became more complex.

- Educators who take the time to dig deeper into games discover a wealth of ideas and possibilities to enrich their practice.

- Teachers, students, and game designers are helping to establish and grow a new "cultural commons" for GBL—an interconnected pool of knowledge, practices, ideas, research, and theories that are shared, used, "hacked," and "modded" to support diverse opportunities for learning. 
The Games for Learning project set out to explore game-based learning (GBL) practices in New Zealand classrooms and build a connected community of research and practice. Our research suggests there is a mixture of curiosity, enthusiasm, and uncertainty in the sector about where games "fit" into learning. I outline some of the theoretical perspectives that have helped me to make sense of 3 years of GBL research, and put forward some ideas that I hope will help GBL research and practice in Aotearoa continue to grow.

\section{Introduction}

Games for Learning was an exploratory research project that began in 2015 with a very broad question: "How can games help learners to develop their potential as expressed in the vision and intentions of The New Zealand Curriculum (Ministry of Education, 2007)?”. Our aim was to investigate how games of all kinds might deepen and enrich students' engagement with learning across the curriculum. We also wondered how students' opportunities to learn might change when teachers experiment with pedagogies linked to, or influenced by, games. Initially we struggled to find the right language to frame our research focus. Terms such as gaming, educational games, serious games, game design, and gamification were all part of the mix, but none of them captured the breadth of what we wanted to explore.

Game-based learning (GBL) has emerged as an umbrella term to encompass all sorts of learning that involves games, or gamification, or both ${ }^{1}$ and comes closest to describing what we were interested in. When we launched the project, it was difficult to piece together a clear picture of GBL practices across New Zealand schools. Most of the substantive research and theory about games and learning came from international literature. Although we found a few interesting pieces of research from Aotearoa, the field was fragmented, and there wasn't evidence of a connected community of research and practice.

Our project aimed to fill some of these gaps. Over more than 2 years, we scoured the New Zealand and international literature, undertook fieldwork in 14 schools, and interviewed dozens of teachers and more than a hundred students from Year 3 to Year 13. We looked at learning and teaching practices involving all kinds of games (physical, role play, tabletop, and digital). We sought to understand the relationships between playing games, designing games, and "gamification", and how these different facets of GBL fitted in with teachers' curriculum and pedagogical goals. We explored teachers' and students' perceptions of games, and what they felt they could learn through games and GBL. In addition to the school-based research, we established a blog and online community, convened workshops for teachers, organised meetups, and ran the 2017 NZCER Games for Learning conference.

Nearly 3 years since we began our project, there have been some important developments in the landscape for GBL research in Aotearoa New Zealand. We're seeing the beginnings of a more connected community of researchers and practitioners sharing knowledge about GBL. Interest in play-based learning has also been steadily growing within the school sector. The recent addition of new digital technologies / hangarau matahiko content in the national curriculum has drawn attention to digital learning activities such as coding, computational thinking, and the design and development of digital outcomes, all of which have strong synergies with digital-game design.

These factors highlight the importance of having a robust platform of Aotearoa-based research and theories to inform curriculum design and pedagogies that utilise the potential of games in the service of educationally meaningful goals. I think there is still a mixture of curiosity, enthusiasm, and uncertainty in the sector about where games "fit" into learning. In this article I outline some of the theoretical perspectives that have helped me to make sense of 3 years of GBL research, and put forward some ideas which I hope will help GBL research and practice in Aotearoa continue to grow.

\section{"Do games help learning? Where's the evidence?"}

Every few months, someone contacts me asking if I can point them to research that says whether games or gamification are proven to be effective for learning. Sometimes it's a teacher, sometimes a game developer, 
sometimes a beginning researcher. Usually the person asking thinks that games or gamification are good for learning, but wants reassurance that there is research to back them up.

In fact, there have been many empirical studies that seek to answer these sorts of questions, and systematic reviews and meta-analyses that seek to assess evidence across many studies (e.g., Clark, Tanner-Smith, \& Killingsworth, 2014; Abdul Jabbar \& Felicia, 2015; Hamari, Koivisto, \& Sarsa, 2014). These studies all come to more or less the same conclusion: Yes, games and gamification can lead to a variety of educationally valuable outcomes, and sometimes they can even be more effective than in carefully matched situations when games aren't used. However, authors of most meta-analyses on GBL tend to conclude that "the important question is not if but how games can support learning" (Clark et al., 2014, p. 14, emphasis added). For example, what are the design features of games that are particularly good for particular kinds of learning? What else, besides playing the games, can help develop or strengthen the learning? How do the contextual details of any given instance of GBL affect what happens for particular learners?

\section{Ecological approaches to understanding GBL}

Contemporary GBL literature emphasises the need to recognise the inherent complexity and diversity of GBL in practice. This complexity derives from several sources, including the following.

- The diverse nature of games themselves, and the nature of interactions and learning opportunities afforded by any particular game or game genre.

- The many different ways in which games and game design can be woven into curriculum and pedagogy.

- The diversity and complexity of people — teachers and students-each of whom brings their own particular expectations, life experiences, knowledge, attitudes, skills and so forth to any particular instance of game-based or gamified learning.

Leading researchers in the field advocate taking an ecological approach to GBL research (Salen, 2008, Young \& Slota, 2017). Ecology refers to the branch of biology that deals with the relations and interactions between organisms and their environment, including other organisms, but it can also be used in a more generic sense to describe the set of relationships existing between any complex system and its surroundings or environment. Studies that have looked in close detail at classroom practice with games show the importance of investigating individual teachers' and students' beliefs, expectations, and interpretations of the games they are engaging with, as well as their ideas and beliefs about learning, teaching, and the curriculum (e.g., Prestridge 2017, Bell \& Gresalfi 2017).

\section{How should we talk about games?}

Digital games are what most people seem to think of when we talk about games for learning, but there are good reasons to begin the discussion elsewhere. American GBL researcher Katie Salen notes that debates about the place of digital games in education and wider society over the last few decades have been "overly polemic and surprisingly shallow" (2008, p. 2). Stevens, Satwicz, and McCarthy describe the "Culture Wars" that periodically flare up around digital games, with one side presenting digital games as "mind-numbing, anti-social, low culture activities" and the other presenting them as "wellsprings of new cultural production, positive identity formation, and learning of all shapes and sizes" (Stevens, Satwicz, \& McCarthy, 2008, p. 42).

Early in the Games for Learning project we saw that although there are many game-positive and game-curious teachers, others have a lingering discomfort and suspicion about games, and/or the people who play them. This presented challenges for some teachers and learners who were trying to bring GBL into their practice. Some of these teachers felt they needed to figuratively "close the curtains" when using games in the classroom:

I know that I can get a lot out of [students] using games, but I do feel a bit uncomfortable about it because I don't have a lesson plan that says, "We are learning this reading strategy". I am always thinking how would I justify it, what am I going to do if the principal walks in ... How do I say, "Well here is my lesson plan, this is what we are learning" and [to the principal] it looks like carnage. (Intermediate teacher)

This school is not necessarily open to games. Some of my students complain to me that they are being banned or their internet access taken off them because they were caught playing games by their teachers. (Secondary teacher)

The game-using and game-designing teachers and students we interviewed saw games from an "insider" perspective, but were conscious of the judgements they sometimes perceived from those on the "outside".

It's the concept of the teenage boy in the black hoodie, he's sitting in his dark room gaming and not being able to do anything else. (Primary teacher)

Through our research we have seen that educators who take the time to dig deeper into games discover a wealth of ideas and possibilities to enrich their practice. Opening up conversations about games with learners also seemed to unlock a level of energy and enthusiasm that we don't often see. At times, students' excitement in talking about games (or their own game designs) during research 
interviews built to such a level that they were physically unable to contain themselves in their chairs. They would crowd forward around the interview tables, asking us more questions to try to keep the interview going even after we felt it had reached a natural conclusion. One group of Year 10 boys who had spoken passionately about the role of videogames in their lives and learning for almost an hour said, at the end of the interview:

This is like the most we've like ever talked, and like talked about something we actually wanted to, at school! (Student, Year 10)

These visible signs of students' engagement with games were of great interest to teachers in our project. They used words like "fizzing", "buzzing", and "humming" to describe a dynamic shift of energy and engagement that they observed in their classes when students were playing or making games. As one teacher put it:

Something happens when students start playing games, and I want to understand what that is. (Teacher, Years 7-8)

\section{Games as part of the cultural commons}

It's worth remembering that games are more than a modern digital entertainment media product. Games have existed for millennia. Like any product of human culture, games have served a variety of different purposes in human societies, providing leisure and entertainment, helping to cultivate certain skills and knowledge, and passing on cultural and social norms from one generation to the next.

For most of human history, games and other recreational pastimes were simply part of the "cultural commons" of various communities and societies. A cultural commons can be defined as intergenerational knowledge or a "system of intellectual resources" (Santagata, Bertacchini, Bravo, \& Marrelli, 2011, p. 1) that is created and used by a community. As part of these cultural commons, toys and games across history served "an important function in teaching and consolidating social rules and norms, in establishing skills and transmitting social knowledge, in creating and reinforcing human relations, and providing relaxation and enjoyment" (Heller, 2008, p. 272).

\section{From the commons to commodities}

Traditionally, games were continuously modified, adapted, and tweaked to suit local norms, resources, and worldviews - practices that today would be described as "hacking" or "modding". Many games that are widely known and played today, including Snakes and Ladders, Chess, Backgammon, and Go have very long lineages, with variations spreading into many different parts of the world over hundreds or thousands of years (Parlett,
1999). Games often provided a symbolic representation of life's journey, including "its hardships and successes ... the struggle of the good and the bad, and the power of fate" (Heller, 2008, p. 274). Social, moral, and ethical messages were conveyed through various aspects of the game design, including imagery, game pieces, and game mechanics, forming what Heller (2008) calls the "hidden curriculum" of games. These included ideas about social roles/social order, ${ }^{2}$ the "correct" ways to lead a moral life and find pathways to enlightenment, or the powerlessness of mortals to wholly determine their own fate in a world influenced by capricious gods and demons. Board and card games in 18th- and 19-century Europe and North America often had a strong emphasis on morals and values_-"a quality that helped them gain societal and parental approval” (Pilon, 2015, p.45).

If one was trying to pinpoint when games and education first started growing apart, perhaps it was in late 19th/early 20th century with the emergence of the first highly commercially successful proprietary games. Milton Bradley, an American lithographer and publisher, was one of the first game designers to have widespread commercial success with The Checkered Game of Life, released in 1860 . His game was inspired by earlier American and British games with one key difference. Rather than focusing purely on the quest for moral virtue, Bradley's version framed the idea of a successful life "in secular business terms, depicting life as a quest for accomplishment with personal virtues as a means to that end". ${ }^{3}$ The game was a good fit with the new American meritocratic ideals, in particular the idea that anyone who worked hard enough and had a bit of good luck on their side could find prosperity.

Young American entrepreneur George Swinnerton Parker, who later founded the game company Parker Brothers, also saw an opportunity in games. Growing up in the shipping town of Salem, George and his friends had played all sorts of games from all over the world, including from the Far East (Pilon, 2015). Parker thought most American game inventors of his time were going about things the wrong way - the games they were designing were too educational and "boring".

As a teenager, Parker and his friends invented a card game called Banking, derived from an already-existing game, but with a new rule that allowed players to "borrow" money and try to repay the loan at 10\% interest "thereby vicariously living the real-life highs of investors dancing the tightrope between risk and reward" (Pilon, 2015, p. 47). Parker soon established a successful gamepublishing business and began to buy up the rights to other local game developers, rebranding them as Parker titles (Pilon, 2015). 


\section{Enclosing the commons and ramping up the fun factor}

The games that Parker, Bradley, and other emerging board-game entrepreneurs made their fortunes on were typically based on or inspired by pre-existing games or game mechanics, albeit with novel "twists" on game play that seemed to hook players. This shift towards games as proprietary commodities is an example of "enclosure", defined as "the process of transferring aspects of a culture...that are freely shared by members of the community into what is privately owned-into a commodity or service that has to be purchased" (Bowers, 2009, p. 197). Chess, for instance, "is a traditional or folk game, having no creditable individual inventor and being in the public domain, whereas Monopoly has a named inventor... and is protected by copyright" (Parlett, 1999, p. 5).

Game designers face the continuous challenge of how to make money from their game concepts. One interesting point is that it is almost impossible to copyright a game mechanic. ${ }^{4}$ In traditional folk games, the position of the pieces on the board and the rules governing their movement was the key feature of the game. Many modern board games are variations on traditional "positional" board games, but their appeal and unique features often lie in the themes, stories, visual representations and other copyrightable features designed into the game. In modern tabletop games, the board and pieces account for only part of the equipment, and often the play of the game centres "above" the board, in the minds and interactions of the players themselves (Parlett, 1999, p.7). Gameplay is built around themes such as business and trading, detection and deduction, crime, war, fantasy, alternative histories, politics, sports, social interaction, or practically any other theme a game designer can think of. Fantasy games such as Dungeons and Dragons have basically dispensed with boards altogether, simply using dice, player handbooks, and a great deal of imagination.

Did the emergence of the 20th-century commodified entertainment games, with their emphasis on fun at the expense of moral teachings, form the beginnings of a wedge between games and school learning that still lingers today? Perhaps, though tabletop and card games have managed to find a place in classrooms, particularly "educational" games and those designed for younger players. Mentally engaging and higher quality "recreational" games such as Scrabble, Monopoly, and many others have remained popular for decades, and it's easy to make a case for how they can contribute to literacy or mathematical learning. The educational affordances of other types of games, including popular digital games, may be less evident to the non-gaming teacher.

\section{The professional gap between education design and game design}

Although many adults may be familiar with the Parker Brothers and Milton Bradley games of their childhoods, not all have kept up with the proliferation of high quality, innovative, and sometimes strategically complex tabletop games that have continued to be invented in recent decades, much less the digital games that dominate the gaming landscape. The idea that some people are "gamers" and other people are "not gamers" has taken hold in popular culture, and become even stronger with the rise of digital games. People who play games and participate in game culture have an "insider" perspective on the games they play and why they play them. They have a sense of what's going on in their minds during play, and what sort of interactions they are having with the game, or with other players. This may look entirely different to the non-gamer "outsider", who might wonder why someone would spend so much time and mental energy engaging in something that, for them, seems boring, pointless, a waste of time, or possibly even harmful.

Meanwhile, games have become a specialised field where every element of design is heavily researched, tested, and improved to be as engaging and desirable as possible. Games and game design have become a thriving global industry, said to be worth upwards of $\$ 90$ billion per annum..$^{5}$ In addition to being intrinsically motivated by their professional craft and valuing players' experiences, game designers have strong economic incentives to make their games as engaging and irresistible to players as possible, and have amassed a wealth of knowledge about how to do this. Knowledge about who plays games, how and why they play games, and what makes particular games so enticing is commercially valuable knowledge. It's also educationally valuable knowledge, in the sense that it provides all kinds of insights into how people engage, stay engaged, interact, and learn in an environment that often looks very different to the learning environment of a traditional classroom. The field of game studies has grown into an established, multidisciplinary academic field of study, producing many books, journals, courses of study, professional conferences and associations dedicated to the rigorous study of games and their play. So how can educators who are new to games and game-thinking easily access and use all of this knowledge to grow their confidence and capabilities in GBL? 


\section{Strategies for becoming a game- confident teacher}

One challenge for teachers who may not have spent much time thinking very deeply about games is that when they do start looking, they discover there is so much to know that it can be hard to quickly wrap one's head around it all. In the Games for Learning project, we found that learning about the affordances of GBL often led teachers to rethink some of their existing practices and assumptions, and opened up previously untapped pedagogical opportunities.

We were particularly interested in the journeys of the teachers in our study who said they knew almost nothing about games, when they decided to make games (or game design) a classroom focus. We've seen a range of practices that help teachers to go from "game-curious" to "gameconfident". In no specific order, these are:

- reading, listening, watching, and learning about GBL

- playing and designing games

- jumping in and trying GBL practices

- surfacing and working with students' game knowledge

- connecting with or forming a "tribe" (community of practice).

\section{Reading, listening, watching, and learning about GBL}

There is plenty of worthwhile reading material. Professor James Paul Gee was one of the early educational academics to turn their attention to commercial entertainment games and to consider what educators could learn by looking at how video games help players learn. His 2003 book What Video Games Have to Teach us about Learning and Literacy discusses 36 principles of learning that Gee argues are built in to good video games. Gee and many other researchers have contributed to a now large body of work that pulls apart the inner workings of games to reveal the many ways in which games "work" to keep players motivated and involved. They argue that many games, particularly more complex games, represent finely tuned learning environments that may align more strongly with what we now know about learning and cognition than "traditional" school teaching practices.

A number of recent international books provide detailed analyses of diverse GBL in a diverse range of learning contexts, including Young and Slota (2017), Beavis, Dezuanni, and O’Mara (2017), Farber (2017), Kafai and Burke (2016). However, these books can often be expensive or difficult for teachers in Aotearoa to access. We and other game-curious educators have discovered there are lots of other ways to learn about games and GBL, through free and accessible online content, include online articles, blogs, podcasts, and YouTube channels. As one teacher in our study observed:

Once you start [with a games focus]... you see it everywhere-it opens up a whole new way of thinking (Teacher, Years 5-6)

Some teachers also discovered the benefits of connecting with game developers and game designers, bringing them into schools to work with students, or networking and bouncing curriculum design ideas around together at conferences and meetups.

\section{Playing and designing games}

Game-using teachers thought it was also useful for teachers to expand their own knowledge by finding and playing games that they found engaging, or looking into games that they knew their students liked.

I think definitely like finding some games that you can enjoy yourself so that you can unpack them ... I've found a couple of games which I've played and tried to look at it from that perspective and "Why do I enjoy this so much?" (Teacher, Years 3-4)

Some teachers went further by trying to design games themselves.

It was pivotal for me in [understanding] how complex and challenging making a game is. If I could say anything, [it would be that] if you're going to teach kids how to do gaming, always make one yourself. Which is challenging [but] that's what you're asking kids to do. (Teacher, Years 5-6)

\section{Jumping in and trying GBL practices}

In our research we saw some teachers move from gamecurious to game-confident by jumping in and getting started with GBL practices, even when they weren't sure they knew exactly what they were doing. At one Wellington primary school, a syndicate of four teachers decided they would make games and game design the focus for a term. One beginning teacher admitted that she was not very interested in games.

I don't like sitting down and playing a board game. It just doesn't interest me... So I came in [to the unit] with absolutely nothing basically, and went "Oh yeah this will be something fun to do. Kids like playing games”... I think that was my limited thinking..my lack of understanding or knowledge of games...I couldn't see how it could actually expand (Beginning teacher, Year 5-6)

The teachers in this syndicate brought in a game designer who took students through an activity involving the classic board game Snakes and Ladders.

[The game designer] introduced the word "hack" within the first 10 minutes. The kids were like [gasp]. They thought "are you allowed to do that?". He asked "what do you need to be good at to win Snakes and Ladders?" They 
were trying to guess what was in the adult's head. "You have to be good at rolling the dice?" "You have to be good at counting?" He said "does it involve any skill? Nah. It's just luck". They hadn't really thought of that too much. He said, "So we're going to hack it" (Senior teacher, Years 5-6)

Students formed into groups and started to work on hacks and "all of a sudden the game was developing differently around the room". The idea of hacking left a lasting impression on both students and teachers, including the teacher who had initially said she wasn't too sure about games.

Now I see that you can hack [games] and you can make them suit your needs, and do what you want to do. I think just the idea of hacking has been eye opening for both me and the kids, and we often talk about, "How could we hack this?", and it might not even be a game [but any aspect of our learning] (Beginning teacher, Years 5-6)

The teachers soon realised that what they might have seen as a one-term inquiry was generating ideas and learning opportunities in each classroom that could continue to snowball well beyond a single term. One teacher gave advice for other teachers considering bringing a games focus into their classroom:

I think you've got to go into it committed to the idea. It is an idea that, with kids, picks up a lot of steam very quickly. What you do not want to do is open the door and then try to shut the door again. It may lead to some interesting places in terms of what you normally do... It's about ... using [students'] interests and their engagement as the fuel to keep going wherever it ends up going. (Beginning teacher, Years 5-6)

\section{Surfacing and working with students' game knowledge}

A major driver for many game-using and game-curious teachers was to connect with their students' interests and motivations. Tapping into students' prior knowledge and experiences with games often gave teachers insights into their students' often quite extensive game knowledge.

That was the first time I really noticed that there was a huge wealth of knowledge that existed in my class about games already (Teacher, Years 3-4)

Teachers found that connecting with students over games helped to build trust and openness in the classroom.

There is a culture [in our classroom] of being able to share and things like the game design, and just playing games in general, I think just allows students to feel really empowered. Because it's theirs—and they're the experts, not me. So, I think that's a really good way to really get them showing leadership (Teacher, Years 3-4)

\section{Connecting with, or forming, a "tribe"}

Finally, we observed the importance of teachers having collegial support and networks. Many teachers who came forward to be part of the research in its first year said they largely developed their GBL practice on their own, or sometimes with the support of one or two colleagues. Some teachers mentioned feeling somewhat isolated in their practices. They found it hard to talk to other colleagues about what they were doing. A few teachers confessed to niggling doubts or questions that came up in their own minds from time to time. These included whether they were getting "carried away" with games at the expense of learning, or focusing too much on fun and engagement without being able to "prove" that this would ultimately pay off for students' learning in the long term. Other teachers were less isolated, working in schools where they had a lot of support or could develop and share GBL with colleagues.

Regardless of their circumstances, all the teachers we interviewed were keen to connect, share, and exchange ideas with other game-curious and game-using teachers. Farber (2018), and Malmstrom (2018) in this issue, make reference to "The Tribe", an informal name adopted by a small but globally connected community of GBL practitioners, researchers, and game developers that connects extensively both online and offline to share ideas, practices, and research, provide friendship and support, and mentor emerging GBL educators. Through these communities of practice, teachers, students, and game designers are helping to establish and grow a new "cultural commons" for GBL_ - an interconnected pool of knowledge, practices, ideas, research, and theories that are shared, used, "hacked", and "modded" by the community.

These connected communities also support educational-game design industry professionals to learn from and co-design with teachers and students - a genuinely ecological approach that recognises that the complex contexts, dynamics, and diversity of classroom communities can be designed with as well as designed for.

\section{Conclusion}

This article has skimmed the surface of a vast field of theory, research, and practice relating to games and their diverse roles and functions in learning. I've suggested that some educators have missed out on the opportunity to consider the many interconnected contributions that games can or could play in learning. A "connected" view of gaming (Kafai \& Burke, 2016) involves recognising that learning can occur through playing games, designing games, through the critical study of games, through 
exploring the social histories of games, and through gamification, and that there is no linear pathway through these facets of GBL. It has been our project's goal to help foster a "connected" perspective on GBL through a "connected" community in Aotearoa and this work is ongoing.

\section{Notes}

1. Gamification refers to the use or integration of game elements into a non-game context.

2. For example, chess and card decks which ascribe different degrees of power and mobility to different roles in the social hierarchy

3. See https://en.wikipedia.org/wiki/Milton_Bradley

4. George Parker had several mishaps in his attempts to own the rights to certain games. In the late nineteenth century he bought the US trademark for the game of Tiddlywinks, which was a craze sweeping Europe at the time, but later this was challenged by other companies and eventually the game was deemed to be in the public domain. The same thing later happened with the game of Ping-Pong (Pilon, 2015).

5. In 2017, the New Zealand game development industry generated nearly $\$ 100$ million in revenue, with the vast majority of sales being to the international consumer market. See https://nzgda.com/survey2017/

\section{References}

Abdul Jabbar, A., \& Felicia, P. (2015). Gameplay engagement and learning in game-based learning: A systematic review. Review of Educational Research, 85(4), 740-779.

Beavis, C., Dezuanni, M., \& O’Mara, J. (2017). Serious play: Literacy, learning, and digital games. New York, NY: Routledge.

Bell, A., \& Gresalfi, M. (2017). The role of digital games in a classroom ecology: Exploring instruction with video games. In Michael F. Young \& Stephen T. Slota (Eds), Exploding the castle: Rethinking how video games and game mechanics can shape the future of education (pp. 67-92). Charlotte, NC: Information Age Publishing.

Bowers, C. (2009). Educating for a revitalization of the cultural commons. Canadian Journal of Environmental Education, 14(1), 196-200

Brown, H. (2016). Ngā taonga tākaro II: The matrix. Mount Maunganui: PENZ.

Clark, D., Tanner-Smith, E., \& Killingsworth, S. (2014). Digital games, design, and learning: A systematic review and meta-analysis (executive summary). Menlo Park, CA: SRI International.

Farber, M. (2017). Game-based learning in action: How an expert affinity group teachers with games. New York, NY: Peter Lang.

Gee, J. (2003). What video games have to teach us about learning and literacy. New York, NY: Palgrave Macmillan.
Hamari, J., Koivisto, J., \& Sarsa, H. (2014). Does gamification work? A literature review of empirical studies on gamification. Proceedings of the 47th Hawaii International Conference on System Sciences. IEEE. Retrieved from https://ieeexplore.ieee. org/document/6758978

Heller, M. (2008). Games and the media: The acquisition of social structure and social rules. In K. Drotner and S. Livingstone (Eds), The international handbook of children, media and culture (pp. 271-298). London, UK: Sage.

Kafai, Y., \& Burke, Q. (2016). Connected gaming: What making video games can teach us about learning and literacy. Cambridge, MA: MIT Press.

Malmstrom, M. (2018). Play, games and culture: How games transformed my pedagogical practice. Set: Research Information for Teachers, (3), 78-80.

Ministry of Education. (2007). The New Zealand curriculum. Wellington: Learning Media.

Parlett, D. (1999). The Oxford history of board games. Oxford, UK: Oxford University Press.

Pilon, M. (2015). The monopolists: Obsession, fury, and the scandal behind the world's favourite board game. New York, NY: Bloomsbury, 2015.

Prestridge, S. (2017). The non-gamer teacher, the quiz and pop teacher and the Kinect teacher. In Serious play: Literacy, learning and digital games (87-101). New York, NY: Routledge.

Salen, K. (2008). The ecology of games: Connecting youth, games, and learning. The John D. and Catherine T. MacArthur Foundation Series on Digital Media and Learning. Cambridge, MA: MIT Press.

Santagata, W., Bertacchini, E., Bravo, G., \& Marrelli, M. (2011, January). Cultural commons and cultural communities. Paper presented at Sustaining Commons: Sustaining Our Future, the Thirteenth Biennial Conference of the International Association for the Study of the Commons, Hyderabad, India.

Stevens, R., Satwicz, T., \& McCarthy, L. (2008). In-game, inroom, in-world: Reconnecting video game play to the rest of kids' lives. In K. Salen (Ed.), The ecology of games: Connecting youth, games, and learning. The John D. and Catherine T. MacArthur Foundation Series on Digital Media and Learning. Cambridge, MA: MIT Press.

Young, M., \& Slota, S. (Eds). (2017). Exploding the castle: Rethinking how video games and game mechanics can shape the future of education. Charlotte, NC: Information Age Publishing.

Rachel Bolstad is a senior researcher at NZCER with a strong interest in learning through games and game design. She has organised conferences and workshops for game-curious educators, and blogs about her research. https://www.nzcer.org.nz/blogs/ games-for-learning

Email: Rachel.Bolstad@nzcer.org.nz 